\title{
ARTICLE
}

\section{Therapeutic potential of an anti-HER2 single chain antibody-DM1 conjugates for the treatment of HER2-positive cancer}

Hang Zhang ${ }^{1,2}$, Yuxi Wang ${ }^{1}$, Yangping $W^{1}{ }^{1}$, Xiaohua Jiang ${ }^{1}$, Yiran Tao ${ }^{1}$, Yuqin Yao ${ }^{1,3,4}$, Yujia Peng ${ }^{1}$, Xiangzheng Chen ${ }^{5}$, Yuyin Fu ${ }^{1}$, Lin $\mathrm{Yu}^{1}$, Ruixue Wang ${ }^{1}$, Qinhuai Lai ${ }^{1}$, Weirong Lai ${ }^{1}$, Wenting $\mathrm{Li}^{1}$, Yuhuan Kang ${ }^{1}$, Shuli Yi ${ }^{1}$, Ying Lu ${ }^{1}$, Lantu Gou ${ }^{1}$, Min Wu ${ }^{6}$ and Jinliang Yang ${ }^{1,4}$

Antibody-drug conjugates (ADCs) take the advantage of monoclonal antibodies to selectively deliver highly potent cytotoxic drugs to tumor cells, which have become a powerful measure for cancer treatment in recent years. To develop a more effective therapy for human epidermal growth factor receptor 2 (HER2)-positive cancer, we explored a novel ADCs composed of anti-HER2 scFv-HSA fusion antibodies conjugates with a potent cytotoxic drug DM1. The resulting ADCs, T-SA1-DM1 and T-SA2-DM1 (drug-to-antibody ratio in the range of 3.2-3.5) displayed efficient inhibition in the growth of HER2-positive tumor cell lines and the half-maximal inhibitory concentration on SKBR-3 and SKOV3 cells were both at the nanomolar levels in vitro. In HER2-positive human ovarian cancer xenograft models, T-SA1-DM1 and T-SA2-DM1 also showed remarkable antitumor activity. Importantly, three out of six mice exhibited complete remission without regrowth in the high-dose group of T-SA1-DM1. On the basis of the analysis of luminescence imaging, anti-HER2 scFv-HSA fusion antibodies, especially T-SA1, showed strong and rapid tumor tissue penetrability and distribution compared with trastuzumab. Collectively, the novel type of ADCs is effective and selective targeting to HER2-positive cancer, and may be a promising antitumor drug candidate for further studies.

Signal Transduction and Targeted Therapy (2017) 2, e17015; doi:10.1038/sigtrans.2017.15; published online 19 May 2017

\section{INTRODUCTION}

Antibody-drug conjugates (ADCs), combining an antibody with high cytotoxic small-molecule compounds via a linker, are a new class of highly potent anti-cancer drugs. They have been applied for clinical therapy and showed great promise in recent years. ${ }^{1-3}$ ADCs integrate specific targeting capability of the antibody with high cytotoxicity of the small-molecule compounds, leading to significant improvement of drug efficacy while reducing the side effects. $^{4,5}$ Thus far, there are 2 ADCs (Adcetris and Kadcyla) that have been approved by the Food and Drug Interactions, ${ }^{6,7}$ and over 40 ADCs are currently under clinical evaluations.

Human epidermal growth factor receptor 2 (HER2) is an $185 \mathrm{kDa}$ transmembrane receptor-like protein with tyrosine kinase activity. ${ }^{8,9}$ Although with unknown natural ligand, HER2 can be stimulated by interaction with other family members activated by their ligands and then plays important roles in the process of cell proliferation, differentiation, migration as well as anti-apoptosis. ${ }^{10}$ Because of its high expression in a variety of human cancers (for example, breast cancer, gastric cancer, ovarian cancer, non-smallcell lung cancer and others), HER2 has received great attention in anti-cancer research during the past two decades. ${ }^{11-16}$ Several antibody drugs and small-molecule inhibitors have been approved by the Food and Drug Interactions for HER2-positive cancer therapy. Antibody drugs include trastuzumab (Herceptin,
Genentech), ${ }^{17-19}$ pertuzumab (Perjeta, Genentech) ${ }^{20,21}$ as well as T-DM1 (Kadcyla, Genentech). ${ }^{22,23}$ In addition, there are two classes of small-molecule tyrosine kinase inhibitors targeting HER2, including lapatinib (Tykerb, Novartis) ${ }^{24-26}$ and afatinib (Giotrif, Boehringer Ingelheim). ${ }^{27}$

T-DM1, the conjugates of maytansine derivative DM1 linked to trastuzumab via bifunctional linker SMCC developed by Genentech, is effective in patients with HER2-overexpressing tumors, including some of those who are resistant to trastuzumab itself. ${ }^{28-31}$ Maytansine can inhibit tubulin aggregation via binding with the periwinkle loci on tubulin as a result of promoting apoptosis of tumor cells. ${ }^{32}$ In a phase III clinical trial, overall objective response rate was $43.6 \%$ for patients in the T-DM1 group, and median progression-free survival was 6.4 months, which extended by 3.2 months compared with conventional chemotherapy. ${ }^{33}$ Another ADC, namely, SGN-35, was produced by conjugating anti-human CD30 monoclonal antibody CAC10 with a microtubule inhibitor MMAE. SGN-35 produced a fairly high objective response rate in treating relapsed or refractory Hodgkin's lymphoma and relapsed or refractory systemic anaplastic large cell lymphoma. ${ }^{34-36}$ The median progression-free survival in the SGN-35 arm was extended by 18.8 months compared with the placebo group. ${ }^{37}$ However, intact antibodies generally have inadequate tissue penetrability and diffusivity, which limit the

\footnotetext{
${ }^{1}$ State Key Laboratory of Biotherapy and Cancer Center/Collaborative Innovation Center for Biotherapy, West China Hospital, Sichuan University, Chengdu, China; ${ }^{2}$ Chengdu Rongsheng Pharmaceuticals Co., Ltd., Chengdu, China; ${ }^{3}$ Research Center for Public Health and Preventive Medicine, West China School of Public, Health/No.4 West China Teaching Hospital, Sichuan University, Chengdu, China; ${ }^{4}$ Guangdong Zhongsheng Pharmaceutical Co., Ltd., Dongguan, China; ${ }^{5}$ Department of Liver Surgery and Liver Transplantation Center, West China Hospital, Sichuan University, Chengdu, China and ${ }^{6}$ Department of Biomedical Sciences, University of North Dakota, School of Medicine and Health Sciences, Grand Forks, North Dakota, USA.
}

Correspondence: J Yang (jlyang01@163.com or jinliangyang@scu.edu.cn)

Received 10 October 2016; revised 29 November 2016; accepted 29 November 2016 
therapeutic efficacy of the corresponding ADCs for solid tumors. Engineered antibodies featuring similar binding activity but stronger tissue penetrability, such as Fab, scFv (single-chain variable fragment) and diabody, may be utilized as preferred targeting elements for novel ADCs to increase their therapeutic efficacy.

Compared with the intact antibody, scFv not only has similar binding activity but also has features such as being smaller in size, stronger blood vessels and tissues penetrability and lower immunogenicity. ${ }^{38-41}$ We therefore hypothesized that scFv used as a targeting moiety for delivery of drug may have better therapeutic efficacy against solid tumors. However, scFv has a short half-life in plasma, and this becomes a barrier for its clinical application. ${ }^{42}$ Many engineering approaches have been designed to improve the stability of scFv in plasma, and these approaches are also effective in increasing therapeutic accumulation in tumor sites. Human serum albumin (HSA) is one of the major plasma proteins and an ideal drug delivery carrier. ${ }^{43-47}$ Meanwhile, HSA is ready to accumulate in malignant and inflammatory tissues, which are lack of lymphatic drainage, indicating that HSA has a certain feature of tumor targeting. ${ }^{48}$ Consisting of scFv-HSA fusion antibodies as guiding molecules, the half-life of ADCs can be increased and the in vivo tumor targeting can be enhanced to a certain extent. This will be a new direction in the development of a new generation of ADCs.

In this study, we prepared two types of scFv-HSA fusion antibodies targeting HER2 by transient expression in mammalian cells. Their binding activity, affinity as well as internalization in vitro were investigated. Then, we generated two novel ADCs by conjugating DM1 to anti-HER2 scFv-HSA fusion antibodies and evaluated their in vitro and in vivo antitumor activities. Furthermore, the distribution and penetrability of the anti-HER2 scFv-HSA fusion antibodies in tumor and normal tissues compared with the intact antibody were analyzed. The results showed that the antiHER2 scFv-HSA-DM1 was effective and selective for HER2-positive cancer and may be a promising antitumor drug candidate.

\section{MATERIALS AND METHODS}

\section{Cell lines and culture conditions}

HER2-negative human breast cancer cell lines MCF-7 and MDA-MB-231, HER2-positive human breast cancer cell lines SKBR-3, BT474 and ZR-75-1, and HER2-positive human ovarian cancer cell line SKOV3 were obtained from American Type Culture Collection (Manassas, VA, USA). The cell lines were cultured in high-glucose Dulbecco's modified Eagle medium or Roswell Park Memorial Institute 1640 medium supplemented with 10\% fetal bovine serum (Gibco, Life Technologies, Carlsbad, CA, USA), penicillin $\left(100 \mathrm{U} \mathrm{ml}^{-1}\right)$ and streptomycin $\left(100 \mu \mathrm{g} \mathrm{ml}^{-1}\right)$ at $37^{\circ} \mathrm{C}$ in $5 \% \mathrm{CO}_{2}$. FreeStyle 293-F cell line was obtained from Life Technologies and expanded in FreeStyle 293 Expression Medium (Gibco).

\section{Preparation and characterization of anti-HER2 scFv-HSA fusion} antibodies (T-SA1 and T-SA2)

T-SA1 and T-SA2 were produced in the FreeStyle 293-F mammalian cell transient expression system that was transfected with the plasmids pTT5/T-SA 1 or $\mathrm{p} T \mathrm{~T} 5 / \mathrm{T}-\mathrm{SA} 2$ containing complementary DNA (CDNA) of T-SA1 and T-SA2 proteins, respectively. T-SA1 and T-SA2 contained CDNA of an anti-HER2 scFv designed according to amino-acid sequences of $V_{H}$ and $V_{L}$ regions of trastuzumab with a flexible linker and HSA. CDNA was synthesized by Genscript Biotechnology Company (Nanjing, China). Five days after transfection, expression supernatant was collected and proteins purification was performed in two steps by HiTrap protein L affinity chromatography and Superdex 200 Increase gel filtration chromatography (GE Healthcare, Pittsburgh, PA, USA).

The desired proteins were analyzed by $10 \%$ SDS-polyacrylamide gel electrophoresis (SDS-PAGE) under natural and denaturing conditions. The loading quantity of each sample was kept consistent. The gel was stained with Coomassie Brilliant Blue G-250 (Bio-Rad, Hercules, CA, USA) and image was scanned using the Bio-Rad Gel Doc 2000 imaging system.
The association constant, dissociation constant and affinity of the complexes consisting of anti-HER2 scFv and recombinant extracellular domain of the HER2 receptor p185 $5^{\mathrm{HER} 2 \mathrm{ECD}}$ (Sino Biological, Inc., Beijing, China) were determined by BIAcoreX100 (GE Healthcare) bio-molecular interaction analyzer based on surface plasmon resonance. ${ }^{49}$

\section{Flow cytometric analysis of scFv-HSA fusion antibodies}

Breast cancer cell lines MCF-7, SKBR-3 and BT474, and human ovarian cancer cell line SKOV3 were trypsinized. Cells $\left(1 \times 10^{6}\right)$ were centrifuged, washed with phosphate-buffered saline (PBS) and resuspended in $100 \mu \mathrm{PBS}$ (pH 7.2) or PBS containing trastuzumab, T-SA1 or T-SA2 labeled with fluorescein isothiocyanate (FITC) at the concentration of $10 \mathrm{mg} \mathrm{ml}^{-1}$ at $4{ }^{\circ} \mathrm{C}$ for $30 \mathrm{~min}$, respectively. After incubation, cells were washed three times and resuspended in $500 \mu \mathrm{l} \mathrm{PBS}$. The fluorescence intensity of FITC was determined using flow cytometer (FACSCalibur, BD, San Jose, CA, USA). Three independent experiments of flow cytometric analysis were conducted.

\section{Internalization analysis of scFv-HSA fusion antibodies}

Breast cancer cell lines MCF-7, SKBR-3 and BT474, and human ovarian cancer cell line SKOV3 were trypsinized. Cells $\left(1 \times 10^{6}\right)$ were centrifuged, washed with PBS and incubated with T-SA1 or T-SA2 at the concentration of $10 \mu \mathrm{g} \mathrm{ml}^{-1}$ at $4{ }^{\circ} \mathrm{C}$ for $30 \mathrm{~min}$, respectively. Then, cells were washed three times. The control of each treatment group labeled with Albumin Antibody-FITC conjugate (Thermo Scientific, Waltham, MA, USA) at $4{ }^{\circ} \mathrm{C}$ for 30 min then washed. Others (experimental groups) were resuspended in $100 \mu \mathrm{PBS}$ and incubated at $37^{\circ} \mathrm{C}$ for $1,4,6$ or $8 \mathrm{~h}$, respectively. After incubation, cells were centrifuged and labeled with Albumin Antibody-FITC conjugate at $4{ }^{\circ} \mathrm{C}$ for $30 \mathrm{~min}$. Cells were washed three times and resuspended in $500 \mu \mathrm{l}$ PBS. The fluorescence intensity of FITC was determined using flow cytometer (Novocyte, ACEA Bioscience, San Diego, CA, USA). The following formula was used to calculate the internalization efficiency rate of each agent in cells: internalization efficiency rate $(\%)=$ [(fluorescence intensity of the control group-fluorescence intensity of the experimental group)/ fluorescence intensity of the control group] $\times 100 \%{ }^{50,51}$

To analyze the visualizing distribution of fusion antibodies in cells, each type of breast cancer cell lines (that is, SKBR-3, BT474 and MCF-7) was divided into six parts and plated onto cover slips in six-well plates and then cultured at $37^{\circ} \mathrm{C}$. After $24 \mathrm{~h}$ of culture, two wells of each cell type were incubated with trastuzumab, T-SA1 and T-SA2 labeled with FITC in the concentration of $20 \mathrm{mg} \mathrm{ml}^{-1}$ at $4{ }^{\circ} \mathrm{C}$ for $30 \mathrm{~min}$, respectively. Then, cells were washed with PBS for three times. For control cells, lysosomes were labeled with Lyso-Tracker Red (Beyotime Biotechnology, Shanghai, China). Next, cells were washed with PBS for three times, and fixed in 4\% (W/V) paraformaldehyde at room temperature for $10 \mathrm{~min}$. After washing with PBS for three times, the cell nuclei were labeled with 4,6-diamidino-2phenylindoledihydrochloride (Sigma-Aldrich, St Louis, MO, USA) in the concentration of $1.5 \mathrm{~g} \mathrm{ml}^{-1}$ at room temperature for $5 \mathrm{~min}$. Experimental cells were incubated with culture medium without serum and antibiotics at $37^{\circ} \mathrm{C}$ for $6 \mathrm{~h}$. Then, lysosome dying, cell fixation and nucleus staining were carried out according to the above methods. After extensive wash, visualization of immunofluorescence was observed with fluorescence microscope (Olympus, Tokyo, Japan; TH4-200). ${ }^{52-54}$

\section{Preparation of ADCs}

T-SA1-DM1 and T-SA2-DM1 were two kinds of ADCs by conjugating cytotoxic agent DM1 with scFv-HSA fusion antibodies (T-SA1 and T-SA2) via the free amino group of lysine residues. The ScFv-HSA fusion antibodies and DM1MCC were mixed in a molar ratio of $1: 7.5$ in conjugation buffer $(50 \mathrm{~mm}$ potassium phosphate, $50 \mathrm{~mm}$ sodium chloride, $2 \mathrm{~mm}$ EDTA, pH 7.2) and stirred at $25^{\circ} \mathrm{C}$ overnight. After centrifuged at $17000 \mathrm{~g}$ for $5 \mathrm{~min}$, the supernatant was purified to yield T-SA1-DM1 and T-SA2-DM1 conjugates and replaced to storage buffer ( $50 \mathrm{~mm}$ sodium phosphate, $50 \mathrm{~mm}$ sodium chloride, $\mathrm{pH}$ 7.2) by a size-exclusion chromatography (Thermo Pierce Zeba Spin Desalting Columns and Devices (Thermo Fisher Scientific, Waltham, MA, USA), $7 \mathrm{~K}$ molecular weight cut off). Absorbance of anti-HER2 scFv-HSA-DM1 conjugates was tested at 280 and $252 \mathrm{~nm}$, respectively, and methods for testing drug-toantibody ratios (DARs) of T-SA1-DM1 and T-SA2-DM1 were established basing on differential ultraviolet spectrophotometry.

\section{Analysis of DAR}

ScFv-HSA fusion antibodies absorb strongly at $280 \mathrm{~nm}$ but DM1 absorbs strongly at $252 \mathrm{~nm}$. According to the Lambert Beer's absorption law 
$(A=\varepsilon B C)$, the formulas to calculate total absorbance of anti-HER2 scFv-HSA-DM1 conjugates at 280 and $252 \mathrm{~nm}$ are following:

$A_{280 \text { anti-HER2 scFv-HSA-DM1 }}=\varepsilon_{280 \text { anti-HER2 scFv BC }}$ anti-HER2 scFv $+\varepsilon_{280 \mathrm{DM} 1} \mathrm{BC}_{\mathrm{DM} 1}$

$A_{252 \text { anti-HER2 scFv-HSA-DM1 }}=\varepsilon_{252 \text { anti-HER2 scFv }} C_{\text {anti-HER2 scFv }}+\varepsilon_{252 \text { DM1 }}$ BC $_{\text {DM1 }}$

The extinction coefficients of each component at these wavelengths as follows: $\varepsilon_{280} \mathrm{~T}_{\mathrm{T} S \mathrm{~S} 1}=84545 \mathrm{M}^{-1} \mathrm{~cm}^{-1}, \varepsilon_{280} \mathrm{~T}_{\mathrm{T}-\mathrm{SA} 2}=134645 \mathrm{M}^{-1} \mathrm{~cm}^{-1}$, $\varepsilon_{280} \mathrm{DM} 1=5700 \mathrm{M}^{-1} \mathrm{~cm}^{-1}, \quad \varepsilon_{252} \mathrm{~T}_{\mathrm{T}} \mathrm{SA} 1=39736.15 \mathrm{M}^{-1} \mathrm{~cm}^{-1}, \varepsilon_{252} \mathrm{~T}_{\mathrm{SA} 2}=$ $57897.35 \mathrm{~m}^{-1} \mathrm{~cm}^{-1}, \varepsilon_{252} \mathrm{DM}_{1}=26790 \mathrm{M}^{-1} \mathrm{~cm}^{-1}$. On the basis of the absorbance at 280 and $252 \mathrm{~nm}$, the average molar concentrations of scFvHSA fusion antibodies and DM1 can be calculated. All the tests were taken using PerkinElmer (Boston, MA, USA), Lambda 35, UV/VIS ultraviolet spectrophotometer. The instrument was blanked with storage buffer and samples were diluted to proper concentrations. Three independent measurements were conducted and averages were calculated.

$$
\begin{aligned}
\mathrm{T}-\mathrm{SA} 1-\mathrm{DM} 1 \text { conjugates : } C_{\mathrm{DM} 1} & =\left(A_{252}-0.47 \times A_{280}\right) / 24111 \\
C_{\mathrm{T}-\mathrm{SA} 1} & =\left(4.7 \times A_{280}-A_{252}\right) / 357625.35 \\
\mathrm{DAR} & =C_{\mathrm{DM} 1} / C_{\mathrm{T}-\mathrm{SA} 1} \\
\mathrm{~T}-\mathrm{SA} 2-\mathrm{DM} 1 \text { conjugates }: C_{\mathrm{DM} 1} & =\left(A_{252}-0.43 \times A_{280}\right) / 24339 \\
C_{\mathrm{T}-\mathrm{SA} 2} & =\left(4.7 \times A_{280}-A_{252}\right) / 574934.15 \\
\mathrm{DAR} & =C_{\mathrm{DM} 1} / C_{\mathrm{T}-\mathrm{SA} 2}
\end{aligned}
$$

Characterization of anti-HER2 scFv-HSA-DM1 conjugates

The integrity and purity of anti-HER2 scFv-HSA-DM1 conjugates were verified by SDS-PAGE. Protein concentration was measured based on the method mentioned in the previous section and the loading quantity of each sample was kept consistent. T-SA1, T-SA1-DM1, T-SA2 and T-SA2DM1 were separated on $10 \%$ polyacrylamide gels under natural and denaturing conditions. The gels were stained with Coomassie Brilliant Blue G-250 (Bio-Rad) and images were scanned.

The binding activity comparing anti-HER2 scFv-HSA-DM1 conjugates with their unconjugated antibodies was studied by flow cytometry on HER2-positive cell lines (SKOV3, BT474, SKBR-3 and ZR-75-1) and HER2-negative cell line MCF-7. Trypsinized cells $\left(1 \times 10^{6}\right)$ were centrifuged, washed with PBS and resuspended in $100 \mu \mathrm{l}$ PBS ( $\mathrm{pH}$ 7.2) or PBS containing T-SA1, T-SA1-DM1, T-SA2 or T-SA2-DM1 at the concentration of $10 \mu \mathrm{g} \mathrm{ml}^{-1}$ at $4{ }^{\circ} \mathrm{C}$ for $30 \mathrm{~min}$, respectively. Cells were washed three times with PBS and then labeled with Albumin Antibody-FITC conjugate (Thermo Scientific) at $4{ }^{\circ} \mathrm{C}$ for $30 \mathrm{~min}$. After incubation, cells were washed three times and resuspended in $500 \mu \mathrm{l}$ PBS. The fluorescence intensity of FITC was determined using flow cytometer (Novocyte, ACEA Bioscience). Three independent experiments of flow cytometric analysis were conducted. Furthermore, the affinity of two anti-HER2 scFv-HSA-DM1 conjugates, T-SA1-DM1 and T-SA2-DM1, with the extracellular domain of HER2 was analyzed by surface plasmon resonance technology. ${ }^{55,56}$

\section{In vitro cytotoxicity assay}

The anti-proliferation activity of scFv-HSA fusion antibodies and their conjugates on breast cancer cells (MCF-7, MDA-MB-231 and SKBR-3) and ovarian cancer cells (SKOV3) were determined by Cell Counting Kit-8 assay (Dojindo Laboratories, Kumamoto, Japan). Cells $\left(1.5-6 \times 10^{3}\right.$ per well, changes according to the growth rate of different cells) were seeded in 96-well plates with the volume of $100 \mu \mathrm{l}$ medium for each well. After $24 \mathrm{~h}$ of culture, cells were treated with scFv-HSA fusion antibodies or their conjugates of serial dilutions in culture medium. Each drug concentration was plated in triplicate. After $72 \mathrm{~h}$ of continuous drug exposure, $20 \mu \mathrm{l}$ Cell Counting Kit-8 solution was added to each well, and cells were incubated for another 1-3 $\mathrm{h}$. The absorbance at $450 \mathrm{~nm}$ was measured by microplate reader (Thermo, Multiskcan MK3). All experiments were measured independently in triplicate. The following formula was used to calculate the cell growth inhibition rate of each agent on cells: cell growth inhibition rate $(\%)=\left[\left(A_{450}\right.\right.$ of control $-A_{450}$ of treated cells) $/ A_{450}$ of control] $\times 100 \%$. The half-maximal inhibitory concentration $\left(\mathrm{IC}_{50}\right)$ value of each agent was statistically analyzed by GraphPad Prism 6.0 software (GraphPad Software, Inc., San Diego, CA, USA). 39,57,58

\section{In vivo antitumor activity studies}

Animal experiments were approved by the Institutional Animal Care and Treatment Committee of the State Key Laboratory of Biotherapy in Sichuan
University. Female Balb/c nude mice (age, 4-5 weeks) purchased from (Beijing HFK Bioscience Co., Ltd., Beijing, China) were acclimated for 1 week before the experiment. The SKOV3 ovarian cancer xenograft model was employed to evaluate the in vivo activity of anti-HER2 scFv-HSA-DM1 conjugates comparing with their unconjugated antibodies. Mice were given a single point of subcutaneous injection with SKOV3 cells suspension $\left(1 \times 10^{7}\right.$ cells in $100 \mu \mathrm{l}$ cell culture medium without serum and antibiotics). When the volume of subcutaneous xenografts reached $200 \mathrm{~mm}^{3}$, the mice were divided into five groups $(n=6)$. The scFv-HSA fusion antibodies $\left(20 \mathrm{mg} \mathrm{kg}^{-1}\right)$, their DM1 conjugates $\left(5,10\right.$ and $\left.20 \mathrm{mg} \mathrm{kg}^{-1}\right)$ and control (storage buffer) were administered via tail vein injection to mice on days 0,4 and 8 . Tumor volume and body weight were monitored twice a week. When the volume of subcutaneous xenografts was $>1500 \mathrm{~mm}^{3}$, the mice were killed.

\section{In vivo distribution of ScFv-HSA fusion antibodies}

Human ovarian cancer SKOV3 xenograft model was established as mentioned in the previous section. When the volume of subcutaneous xenografts reached $300 \mathrm{~mm}^{3}$, these mice were divided into four groups $(n=4)$. One nanomolar of trastuzumab, T-SA1 or T-SA2 labeled with Cy5.5 was administered via tail vein injection to mice. At 2, 6, 12 and $24 \mathrm{~h}$ after injection, the distribution of trastuzumab, T-SA1 and T-SA2 in vivo was observed by the luminescence imaging system. Furthermore, tumor specimens at each time point and normal tissues at $12 \mathrm{~h}$ after injection were collected. All tissues were embedded with optimum cutting temperature compound immediately. Then, $5 \mu \mathrm{m}$ frozen sections from the optimal cross-sectional surface were prepared and cell nuclei were stained with 4,6-diamidino-2-phenylindole dihydrochloride. Frozen sections were observed with laser scanning confocal microscope (Leica, Leica Microsystems, Wetzlar, Germany, DM6000CS) to evaluate the in vivo distribution of scFv-HSA fusion antibodies compared with the intact antibody trastuzumab.

\section{RESULTS}

Construction, expression and characterization of anti-HER2 scFv-HSA fusion antibodies

A scFv fused with HSA via linker (GGSGG) formed a single-chain T-SA1 (Figure 1a). This SCFV was composed of amino-acid sequences of $V_{H}$ and $V_{L}$ regions of anti-HER2 monoclonal antibody trastuzumab connected by a flexible linker $\left(\mathrm{G}_{4} \mathrm{~S}\right)_{4}$. T-SA2 was composed of two tandem trastuzumab scFvs connected by linker $\left(G_{4} S\right)_{4}$ fusing with HSA via linker (GGSGG). The $V_{H}$ and $V_{L}$ regions of ScFv were connected by linker (GG; Figure 1a). Anti-HER2 scFv-HSA fusion antibodies were transiently expressed in FreeStyle 293-F cells, and purified by protein L affinity chromatography and Superdex 200 Increase gel filtration chromatography. AntiHER2 scFv-HSA fusion antibodies migrated on 10\% SDS-PAGE at the expected molecular weight of 92.9 (T-SA1) and $117.9 \mathrm{kDa}$ (T-SA2) (Figure 1b).

The binding affinity of T-SA1 with recombinant extracellular domain (ECD) of HER2 was $5.910 \times 10^{-11} \mathrm{M}$ by surface plasmon resonance analysis, whereas that of T-SA2 was $1.300 \times 10^{-10} \mathrm{M}$. The association rate constants of the two antibodies were both at $10^{5} \mathrm{M}^{-1} \mathrm{~s}^{-1}$ level, which was at the same level as trastuzumab. This result indicated that both T-SA1 and T-SA2 have high affinity for HER2 receptor. Furthermore, the binding activity of T-SA1 and T-SA2 with HER2-positive cells was investigated by flow cytometry. As shown in Figure 1c, though slightly inferior shift extent compared with trastuzumab, T-SA1 and T-SA2 could specifically bind to HER2positive cells instead of MCF-7 cell with low expression of HER2, indicating that anti-HER2 scFv-HSA fusion antibodies have good binding activity to HER2-positive tumor cells.

\section{Internalization of scFv-HSA fusion antibodies}

To examine whether the scFv-HSA fusion antibodies could specifically internalize into HER2-positive tumor cells and study the internalization efficiency, the uptake of T-SA1 and T-SA2 in three kinds of HER2 high-expression cells (that is, BT474, SKBR-3 and SKOV3) was semi-quantified by flow cytometry assay. As shown in Figure 2a, along with the extension of incubation time, the magnitude of FITC peak shift decreased gradually, which 
a

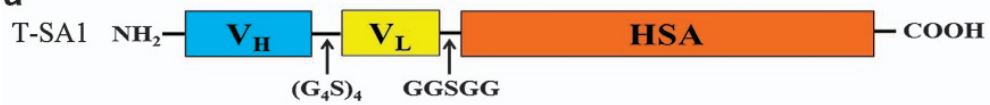

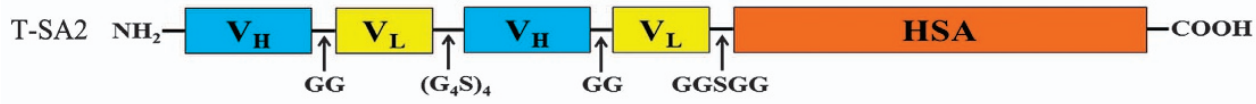

b

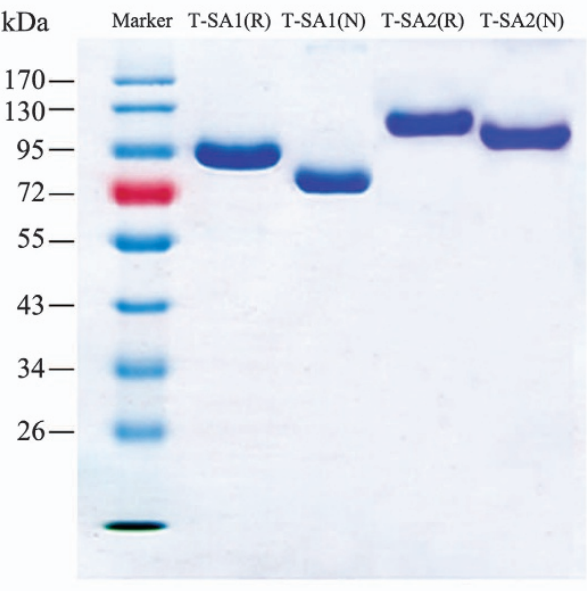

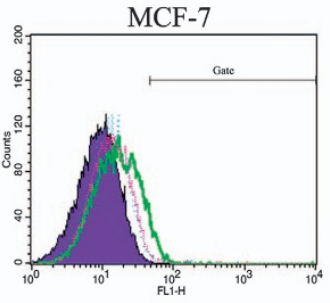
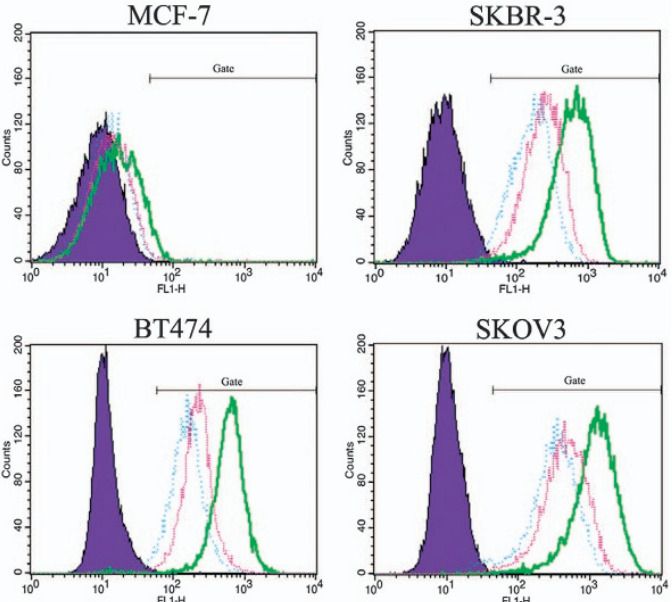

Figure 1. Preparation and characterization of T-SA1 and T-SA2. (a) Schematic diagram of T-SA1 and T-SA2 containing anti-HER2 scFv, the linkers and HSA. (b) SDS-PAGE analysis of purified T-SA1 and T-SA2. T-SA1 and T-SA2 loaded with reducing (R) and non-reducing loading buffer $(\mathrm{N})$ were separated on a 10\% polyacrylamide gel. Marker: PageRuler PlusPrestained-Protein Ladder. (c) Binding activity analysis of T-SA1 and T-SA2 in HER2-negative and -positive cells by flow cytometry. The results indicated that T-SA1 and T-SA2 could specifically bind to HER2positive cells. Blue violet: control group; green: anti-HER2 monoclonal antibody trastuzumab; pink: T-SA1; blue: T-SA2.

represented an increasing number of ScFv-HSA fusion antibodies were taken by cells. After incubating at $37^{\circ} \mathrm{C}$ for $4 \mathrm{~h}$, the internalization efficiency of both T-SA1 and T-SA2 reached $\sim 50 \%$ in average in BT474 and SKBR-3 cells, and $\sim 30 \%$ in SKOV3 cells (Figure 2b).

The distribution of T-SA1 and T-SA2 in HER2-positive cells SKBR-3 and BT474 as well as MCF-7 with low HER2 expression was detected via immunofluorescence. As shown in Figure 2c, the signal of fusion antibodies can be observed mainly on cellular membrane when incubated at exactly $4{ }^{\circ} \mathrm{C}$. However, after internalization at $37{ }^{\circ} \mathrm{C}$, the scFv-HSA fusion antibodies appeared as green spots in the endochylema of SKBR-3 and BT474 cells, but not in MCF-7 cells. By co-localizing with red staining of lysosome, we found that some green spots of antibodies and receptor complexes could overlap with the red spots of lysosomes and then displayed yellow-orange fluorescence. These results indicated that scFv-HSA fusion antibodies could enter lysosome degradation pathway after internalizing into cells.

Preparation and characterization of scFv-HSA-DM1 conjugates Anti-HER2 scFv-HSA fusion antibodies and DM1-MCC were conjugated via the free amino group of lysine residue in neutral reaction buffer. T-SA1 and T-SA2 were exchanged into reaction buffer ( $50 \mathrm{~mm}$ potassium phosphate, $50 \mathrm{~mm}$ sodium chloride, $2 \mathrm{~mm}$ EDTA, pH 7.2) using AKTA Purifier 100 and Hitrap desalting column system (GE Healthcare, Pittsburgh, PA, USA). Dry powder of DM1MCC was dissolved in dimethyl formamide and then mixed with scFv-HSA fusion antibodies in a molar ratio of 7.5:1 and volume ratio of $1: 9$ for the reaction at $25^{\circ} \mathrm{C}$ for $12 \mathrm{~h}$. After reaction, precipitate was removed by centrifuging at $17000 \mathrm{~g}$ for $5 \mathrm{~min}$ and the free drug linkers were removed using Zeba Spin Desalting Columns (Thermo Fisher Scientific, Waltham, MA, USA). The DAR of scFv-HSA-DM1 conjugates was measured based on differential ultraviolet spectrophotometry. With higher molar ratio of DM1-
MCC and antibodies or longer reaction time, high DAR could be obtained. Because of the hydrophobicity of DM1, scFv-HSA-DM1 conjugates become increasingly unstable with the increase of DAR. To maintain the stability of scFv-HSA-DM1 conjugates, the DAR of scFv-HSA-DM1 conjugations of each batch was kept between 3.2 and 3.5. As shown in Figure 3a, T-SA1-DM1 and T-SA2-DM1 showed similar electrophoretic behaviors with their unconjugated antibodies by SDS-PAGE analysis, except as lightly larger molecular weight because of the loaded DM1.

To examine whether conjugation with small molecules could affect the affinity and binding activity of scFv-HSA-DM1 conjugates, surface plasmon resonance analysis and flow cytometry assay were performed. According to surface plasmon resonance analysis, the affinity of these two conjugates was still in the same order of magnitude with antibodies before conjugation (T-SA1-DM1:T-SA1, $9.777 \times 10^{-11}$ vs $5.910 \times 10^{-11} \mathrm{M}$; T-SA2-DM1:T-SA2, $1.285 \times 10^{-10}$ vs $\left.1.300 \times 10^{-10} \mathrm{M}\right)$. As shown in Figure 3b, T-SA1-DM1 and T-SA2DM1 showed the same binding activity as their unconjugated counterparts to HER2-positive cells (that is, SKOV3, BT474, SKBR-3 and ZR-75-1) and HER2-negative cell (MCF-7). These results indicated that conjugation of ScFv-HSA fusion antibodies with appropriate small molecules did not affect the association and dissociation process of antibodies for HER2 receptor. Meanwhile, DM1-MCC might not conjugate in the key binding region with antigen of scFv-HSA fusion antibodies so that it did not affect the binding activity.

\section{In vitro cytotoxicity}

The anti-proliferative activities of T-SA1-DM1 and T-SA2-DM1 on HER2-positive cells (SKOV3 and SKBR-3) and HER2-negative cells (MCF-7 and MDA-MB-231) were compared with T-SA1 and T-SA2 using Cell Counting Kit-8 assay, respectively. After $72 \mathrm{~h}$ exposure, the absorbance at $450 \mathrm{~nm}$ was measured and the $\mathrm{IC}_{50}$ values obtained were summarized in Table 1. ScFv-HSA-DM1 
a
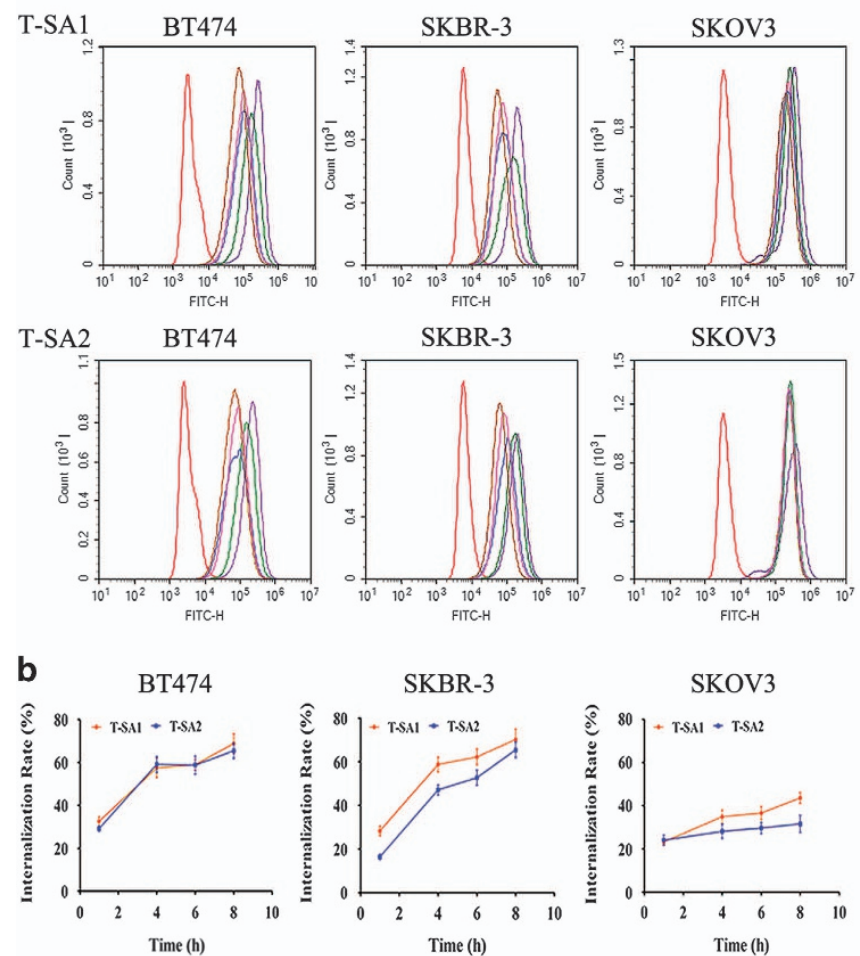

Time (h)

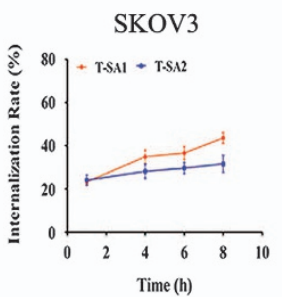

C
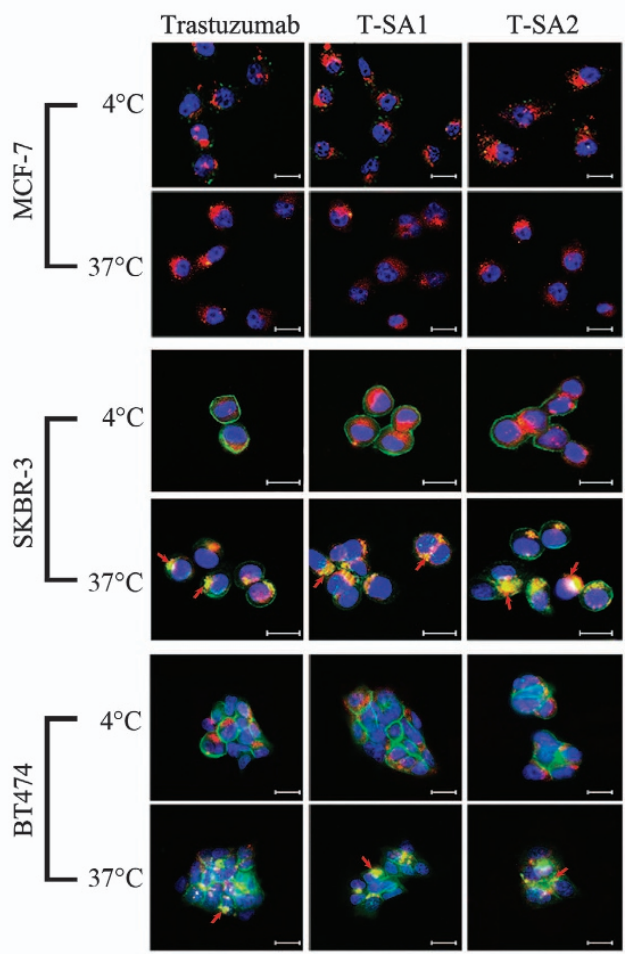

Figure 2. Internalization of T-SA1 and T-SA2 into HER2-positive cells detected by flow cytometry and immunofluorescence. (a) Flow cytometric analysis to evaluate the internalization efficiency of T-SA1 and T-SA2 in BT474, SKBR-3 and SKOV3; red: negative control group; purple: $0 \mathrm{~h}$ group; green: $1 \mathrm{~h}$ group; blue: $4 \mathrm{~h}$ group; pink: $6 \mathrm{~h}$ group; brown: $8 \mathrm{~h}$ group. (b) Uptake of scFv-HSA fusion antibodies in HER2-positive cells increased with time. (c) Internalization of trastuzumab, T-SA1 or T-SA2 into MCF-7, SKBR-3 and BT474 cells (scale bars, $12.5 \mu \mathrm{m}$ ). Cells were incubated with antibodies at $4{ }^{\circ} \mathrm{C}$ for $30 \mathrm{~min}$. Unbinding antibodies were washed away. The experimental groups were incubated at $37{ }^{\circ} \mathrm{C}$ for $6 \mathrm{~h}$.The green spots as shown were antibodies labeled with FITC. The blue spots were cell nuclei stained with 4,6-diamidino-2-phenylindole dihydrochloride. The red spots were lysosomes stained with Lyso-Tracker Red. The yellow to orange spots in the endochylema that were shown with the red arrows were the internalized antibodies co-localized with lysosomes.

conjugates, similar to T-SA1 and T-SA2, showed little to no specific cytotoxicity on MCF-7 and MDA-MB-231 with low expression of HER2. The $72-\mathrm{h} I \mathrm{IC}_{50}$ values of scFv-HSA-DM1 conjugates were $>1200$ and $750 \mathrm{~nm}$ respectively. In contrast, SKBR-3 cells with high level of HER2 expression were killed efficiently by both T-SA1-DM1 and T-SA2-DM1, with $\mathrm{IC}_{50}$ value of $1.05 \pm 0.03$ and $1.10 \pm 0.09 \mathrm{~nm}$. For another HER2-positive SKOV3 cells, T-SA1-DM1 and T-SA2-DM1 also showed outstanding inhibition and the $\mathrm{IC}_{50}$ values were $3.18 \pm 0.49$ and $3.57 \pm 0.45 \mathrm{~nm}$, respectively. However, the cell growth inhibition of ScFv-HSA fusion antibodies on HER2-positive cells was not obvious even though their concentration reached $1200 \mathrm{~nm}$. Compared with the unconjugated antibodies, anti-HER2 scFv-HSA-DM1 conjugates had stronger antiproliferative activities on HER2-positive tumor cells. These data also indicated that high levels of cell surface HER2 were required for specific binding. Meanwhile, anti-proliferative activity was based on the internalization of conjugates and release of cytotoxic molecules DM1 by lysosomal degradation.

\section{In vivo antitumor activity}

The antitumor activity of anti-HER2 scFv-HSA-DM1 conjugates, T-SA1-DM1 and T-SA2-DM1, was evaluated in HER2-positive human ovarian cancer xenograft models. Tolerability experiment was done prior to antitumor activity experiments in mice. Both the scFv-HSA-DM1 conjugates and unconjugated antibodies showed well tolerated at the dose of $30 \mathrm{mg} \mathrm{kg}^{-1}$ administrated via intravenous injection.
Then tumor-bearing BALB/C nude mice were injected via tail vein with scFv-HSA-DM1 conjugates $\left(5,10\right.$ and $\left.20 \mathrm{mg} \mathrm{kg}^{-1}\right)$, unconjugated scFv-HSA fusion antibodies $\left(20 \mathrm{mg} \mathrm{kg}^{-1}\right)$ and control (storage buffer) on days 0,4 and 8. As shown in Figures $4 \mathrm{a}$ and $\mathrm{c}$, treatment with both scFv-HSA-DM1 conjugates and their unconjugated antibodies exhibited suppression of xenografts growth compared to controls. However, scFv-HSADM1 conjugates showed better antitumor activity than fusion antibodies even though at lower doses. Significant inhibition of tumor growth was observed with $20 \mathrm{mg} \mathrm{kg}^{-1}$ T-SA1-DM1- or T-SA2-DM1-treated groups, especially the T-SA1-DM1 treatment group, three out of six mice showed complete remission without regrowth. Tumor growth inhibition presented a dose-dependent effect. More than 1 week after drugs removal, the substantial tumors with non-complete remission in conjugate treatment group started to re-grow, but they showed slower growth rate compared to tumors in the control group and even in unconjugated antibody treatment group. Body weight was monitored twice a week and increased steadily in the treatment group, indicating that toxic effects were not obvious (Figures $4 \mathrm{~b}$ and $\mathrm{d}$ ). These findings indicated that scFv-HSA-DM1 conjugates, especially T-SA1-DM1, not only exhibited potent antitumor activity but also were well tolerated in the xenograft model.

In vivo distribution of ScFv-HSA fusion antibodies To clarify the tumor-binding activity and distribution of T-SA 1 and T-SA2 in vivo, trastuzumab, T-SA1 and T-SA2 labeled with Cy5.5 were administered via tail vein injection to tumor-bearing $B A L B / C$ 

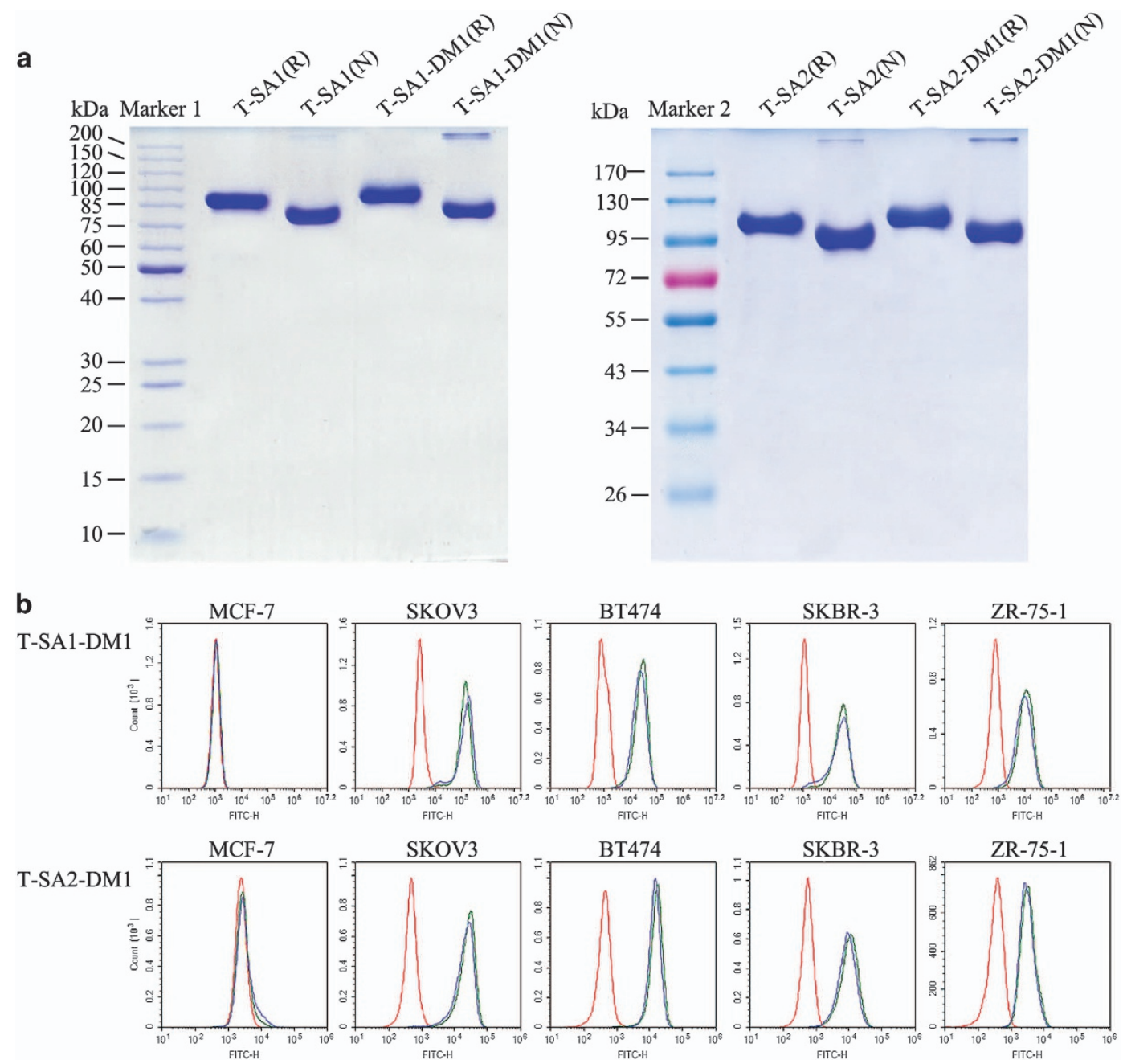

Figure 3. Characterization and comparison of scFv-HSA-DM1 conjugates. (a) SDS-PAGE analysis of scFv-HSA fusion antibodies and their conjugates. T-SA1, T-SA1-DM1, T-SA2 and T-SA2-DM1 loaded with reducing (R) and non-reducing loading buffer (N) were separated on 10\% polyacrylamide gel. The images indicated that the anti-HER2 scFv conjugates showed similar electrophoretic behaviors with their unconjugated antibodies. Marker 1: PageRuler Unstained-Protein Ladder; marker 2: PageRuler Plus Prestained-Protein Ladder. (b) Binding activity of T-SA1-DM1 and T-SA2-DM1 to HER2-negative and -positive cells assessed by flow cytometry. T-SA1-DM1 and T-SA2-DM1 showed the same binding activity as their unconjugated antibodies. Red: negative control; green: T-SA1 or T-SA2; blue: T-SA1-DM1 or T-SA2-DM1.

Table 1. In vitro cytotoxicity of T-SA1-DM1 and T-SA2-DM1 (72 h exposure, $\left.I_{50}, \mathrm{~nm}\right)$

\begin{tabular}{lcccc}
\hline Material & MCF-7 & MDA-MB-231 & SKOV3 & SKBR-3 \\
\hline T-SA1 & $>1200$ & $>1200$ & $>1200$ & $>1200$ \\
T-SA1-DM1 & $>1200$ & $>750$ & $3.18 \pm 0.49$ & $1.05 \pm 0.03$ \\
T-SA2 & $>1200$ & $>1200$ & $>1200$ & $>1200$ \\
T-SA2-DM1 & $>1200$ & $>750$ & $3.57 \pm 0.45$ & $1.10 \pm 0.09$ \\
\hline
\end{tabular}

nude mice and the images were collected by bioluminescence imaging system at 2, 6, 12 and $24 \mathrm{~h}$ post injection. As expected, both T-SA 1 and T-SA2 groups were found under higher intensity in tumor tissues than normal tissues at $2 \mathrm{~h}$ post injection and to produce increasing signals over time until $12 \mathrm{~h}$ post injection as shown in Figure 5. In addition, among the three antibodies, T-SA1 showed the best tumor targeting property and the least accumulation in other organs. These phenomena might be due to the stronger penetrability of small molecular antibody. On the other hand, the capacity of HSA that is easy to accumulate in malignant and inflammatory tissues and to be utilized for tumor proliferation by their degradation products may play a role in the tumor accumulation in solid tumors.

To confirm precise distribution of T-SA1 and T-SA2 within the tumor tissues and main organs, tumors collected at each time point and organs (heart, liver, spleen, lung and kidney) collected at $12 \mathrm{~h}$ post injection were used for producing frozen sections. Frozen sections were observed under confocal microscope as shown in Figure 6. Trastuzumab, T-SA1 and T-SA2 were detected in red fluorescence and cell nuclei were detected in blue fluorescence. Frozen sections of different organs collected at $12 \mathrm{~h}$ post injection exhibited a little staining of fusion antibodies in liver and kidney tissues but not in other normal organs (Figure 6a). The red fluorescence of antibodies in the major metabolic organ liver and excretory organ kidney tissues appeared diffuse distribution in intercellular regions. However, in tumor tissues, antibodies mainly accumulated in the cytoplasm. These results verified that T-SA1 and T-SA2 had highly specific binding to HER2positive tumor cells and efficient internalization in vivo.

As shown in Figure 6b, three different antibodies accumulated in the tumor areas gradually over time with the in vivo circulation. 

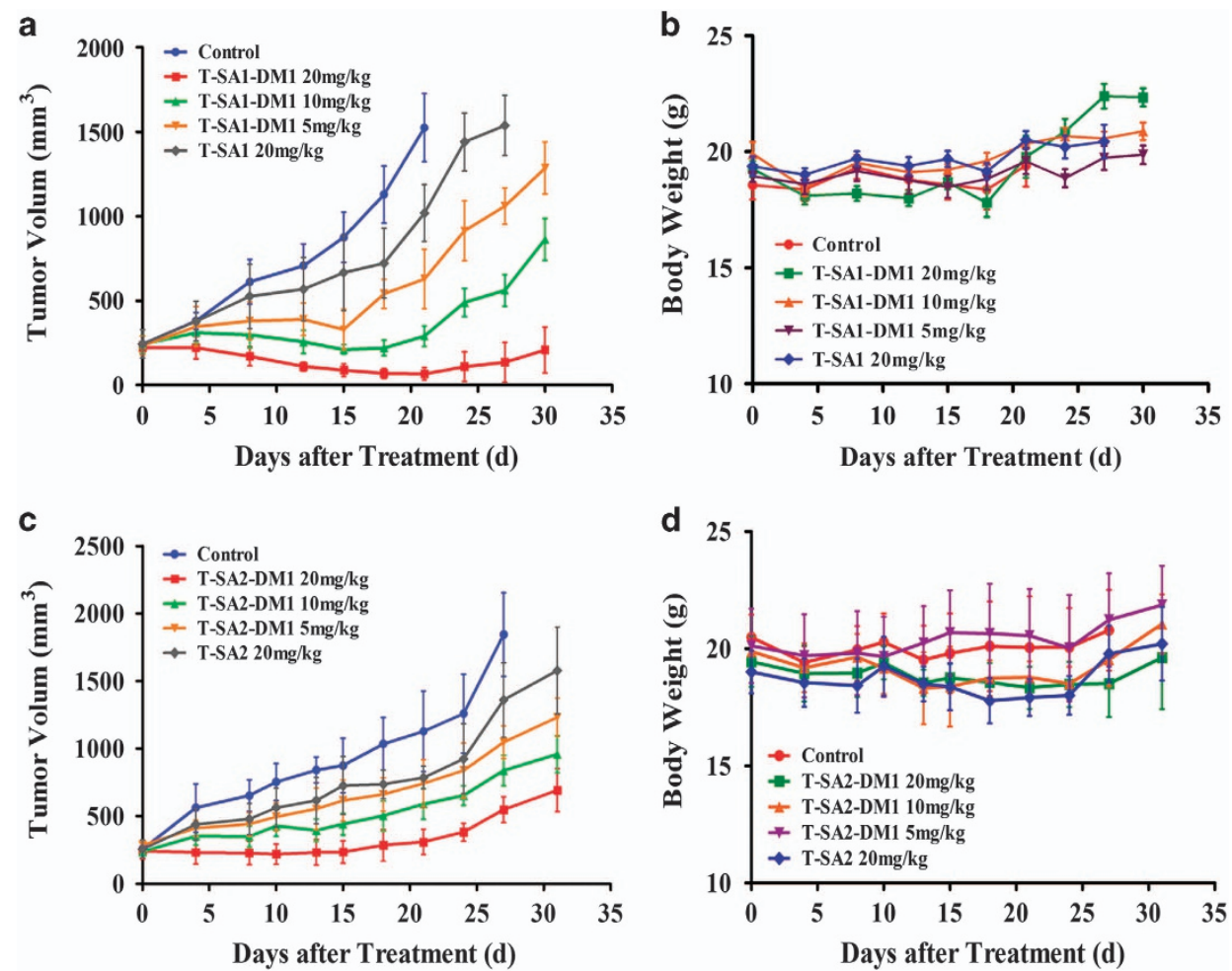

Figure 4. Antitumor activity of T-SA1-DM1 and T-SA2-DM1 against SKOV3 ovarian cancer xenografts. (a) Subcutaneous tumor-bearing mice were treated with storage buffer, T-SA $1\left(20 \mathrm{mg} \mathrm{kg}^{-1}\right)$ and T-SA1-DM1 $\left(5,10\right.$ and $\left.20 \mathrm{mg} \mathrm{kg}^{-1}\right)$; (c) subcutaneous tumor-bearing mice were treated with storage buffer, T-SA2 $\left(20 \mathrm{mg} \mathrm{kg}^{-1}\right)$ and T-SA2-DM1 $\left(5,10\right.$ and $\left.20 \mathrm{mg} \mathrm{kg}^{-1}\right)$. Average tumor volumes were calculated and presented as growth curves. The body weight of nude mice did not change significantly during the treatment with T-SA1-DM1 (b) or T-SA2DM1 (d).
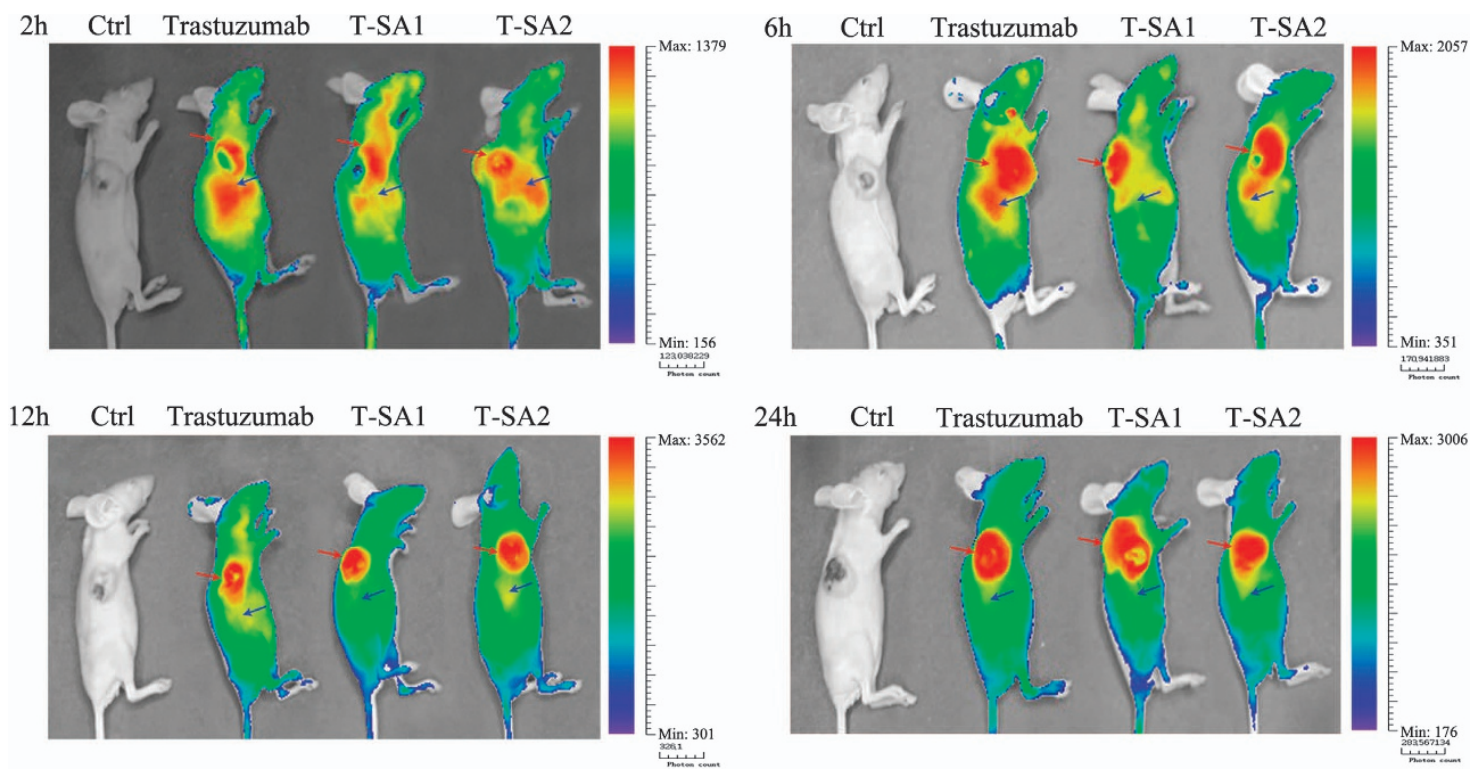

Figure 5. Distribution of trastuzumab, T-SA1 and T-SA2 in vivo was displayed by bioluminescence imaging system. Both T-SA1 and T-SA2 could target tumor tissues specifically within $2 \mathrm{~h}$ post injection and the maximum fluorescence intensity on the area of tumor was observed at $12 \mathrm{~h}$ post injection. The tumor tissue areas were shown with the red arrows. The liver areas were shown with the blue arrows.

As we expected, T-SA2 showed wider distribution than the intact antibody trastuzumab in the tumor tissues. T-SA1, which was visible all over the tumors, appeared to accumulate best among three antibodies in the tumor tissues, and this might in part because of the strong tissues penetrability in solid tumor due to its small molecular size.

\section{DISCUSSION}

The release mechanism of cytotoxic drugs from ADCs is believed to occur after distribution in plasma, diffusion in tumor tissue, binding with cell surface antigen, internalization and degradation of the antibody component in lysosomes. ${ }^{59}$ Therefore, due to the limited tissue penetration of intact antibody, ADCs face enormous 
a

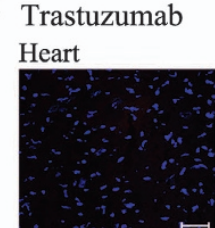

Liver

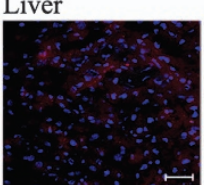

Spleen

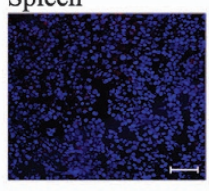

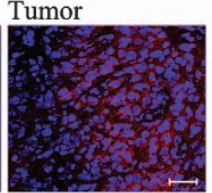

T-SA1

Heart

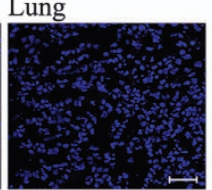

Kidney

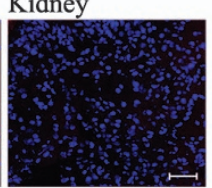

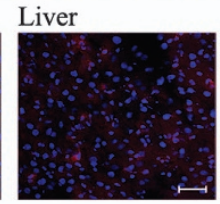

Spleen
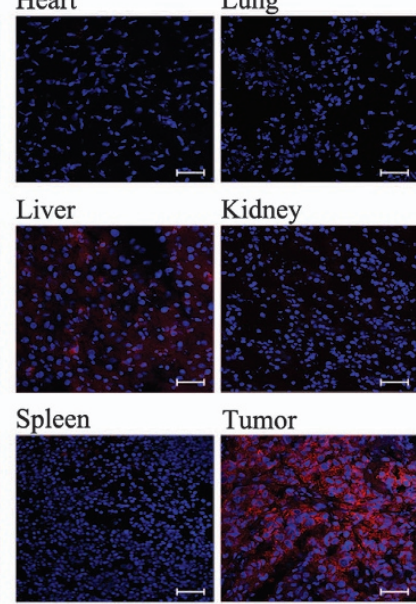

Kidney

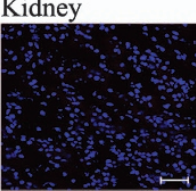

Tumor

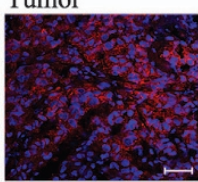

T-SA2

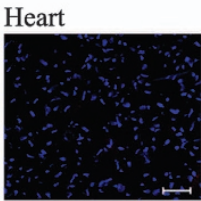

Lung

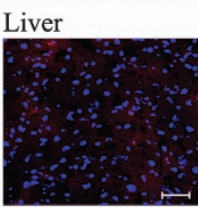

Spleen

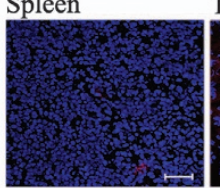

Tumor b $2 \mathrm{~h}$

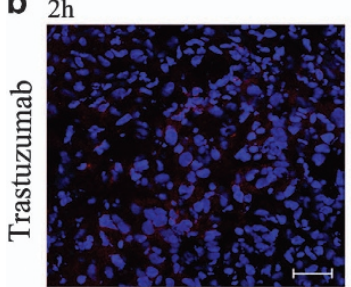

$6 \mathrm{~h}$

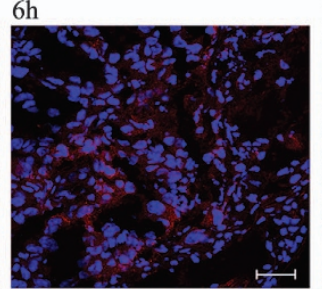

$12 \mathrm{~h}$

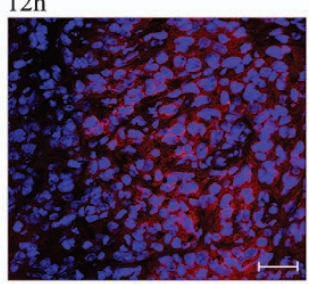

$24 \mathrm{~h}$
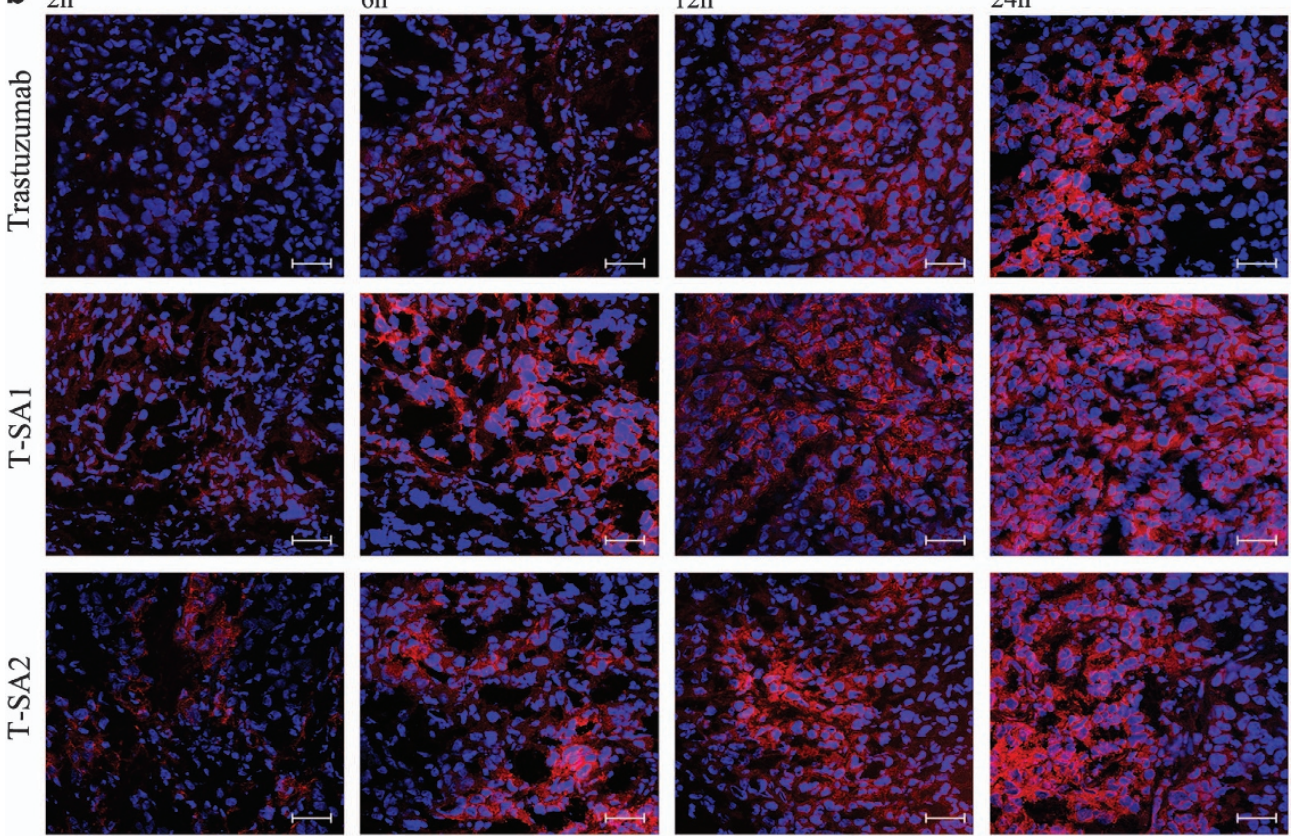

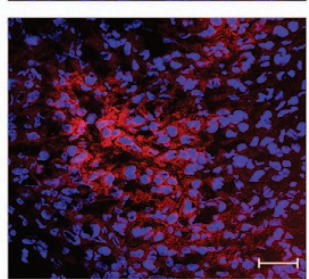

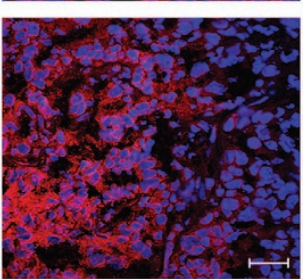

Figure 6. Immunofluorescence of tumor and primary organs samples after injection of trastuzumab, T-SA1 and T-SA2 (scale bars, $50 \mu \mathrm{m}$ ). Trastuzumab, T-SA1 and T-SA2 were detected in red fluorescence and cell nuclei were detected in blue fluorescence. (a) The same as trastuzumab, T-SA1 and T-SA2 distributed in tumor, liver and kidney tissues at $12 \mathrm{~h}$ post injection. Rather than appeared diffuse distribution in intercellular substance of liver and kidney tissues, antibodies accumulated in the cytoplasm in entire tumor tissues. (b) The fluorescence intensity of antibodies in tumor tissues increased with time. Among the three antibodies, T-SA1 had the widest distribution in tumor tissues.

challenges in more effective treatment against solid tumors. To improve tumor tissue penetration and thus therapeutic efficacy, we developed a novel type of ADCs composed of anti-HER2 scFvHSA fusion antibodies conjugated with the potent cytotoxic drug DM1 for HER2-positive cancer therapy.

The two anti-HER2 scFv-HSA fusion antibodies produced by transient expression system ${ }^{60-63}$ kept similar binding activity and high affinity as trastuzumab, and also could internalize into cells quickly as well as enter lysosome degradation pathway. On the basis of their characteristics, two ADCs complexes T-SA1-DM1 and T-SA2-DM1 were prepared, which were composed of scFv-HSA fusion antibodies conjugated with maytansine derivative DM1 on the sites of lysine residues via MCC linker. Published reports indicated that thioether (MCC) linker-containing ADCs not only internalized into tumor cells after binding to receptor on cell surface and undergo proteolytic degradation in the lysosome to release cytotoxic agents, but also maintained plasma stability more effectively. ${ }^{57,59,64,65}$ Clearly, high DAR results in ADCs with increased hydrophobicity and greater degree of destabilization. To ensure stability in pharmaceutically acceptable solvents, antigenbinding ability and antitumor activity of ADCs complexes, conjugation process was optimized to control the DAR of each batch in the range of 3.2-3.5.6,67 As expected, T-SA1-DM1 and T-SA2-DM1 had the same specific binding activity and affinity compared with their unconjugated antibodies, but showed significant inhibitory effect on the growth of HER2-positive cells and remarkable antitumor activity in mouse models. In addition, we also compared the in vivo antitumor activity of T-SA1-DM1 and T-SA2-DM1 with T-DM1 to evaluate the potential for the development of scFv-DM1 conjugates. Under the conditions of the same dose of injection $\left(10 \mathrm{mg} \mathrm{kg}^{-1}\right), \mathrm{T}-\mathrm{SA} 1-\mathrm{DM} 1$ showed similar inhibition of tumor growth with T-DM1 (data not shown). 
This result suggests that scFv-HSA-DM1 conjugates represent a promising antitumor drug candidate and warrant further study.

In general, therapeutic efficacy of ADCs is attributed to the combination of various factors. The mechanisms, including offtarget effects, poor tissue penetration, low affinity, lack of internalization or drug resistance, may cause the disappointing treatment outcome., ${ }^{4,6-70}$ Such problems may be mitigated by designing conjugates that are in a protected form during the delivery and activated after binding to the target cells and internalization. ${ }^{71}$ Multiple reports further contend that antibody size and valence regulating in vivo tumor targeting and biodistribution are closely correlated with antitumor activity of ADCs. Therefore, ADCs consisting of intact antibodies that have relatively large molecular weight and limited tissue penetrability may be less effective in the treatment of solid tumors. Engineered antibodies featuring small size, high specificity with tumor tissues in vivo, and strong blood vessels and tissue penetrability, such as Fab, scFv and diabody, become potential guiding molecules of ADCs. ${ }^{39,40,72}$ However, the major obstacle on the clinical application of antibodies with small size lies in their short plasma half-life. Proteins with molecular weight above $55 \mathrm{kDa}$ do not undergo first-pass elimination through the kidney, thus they have prolonged in vivo biodistribution. ${ }^{73}$ In this respect, modifications of antibody properties, like fusion with carrier proteins, PEGylation and linking with nanoparticles may strongly influence pharmacokinetics. $^{74}$ In this study, anti-HER2 scFvs were fused with HSA as the guiding molecules of ADCs. The in vivo distribution experiment confirmed the corollary that T-SA 1 with the smallest molecular weight possessed the best tumor targeting property and the least accumulation in other organs compared with trastuzumab even T-SA2, hence a highly specific delivery system. We suspected that the greater in vivo tumor targeting might be due to the higher penetrability of small molecular antibody and the characteristic of accumulation in malignant and inflammatory tissues of HSA, ${ }^{75-78}$ but the exact mechanism was unclear and in need of an accurate measure of pharmacokinetics and further verification.

Besides limited tissue penetration of ADCs, lacking efficient internalization of antibody component is another reason of disappointing treatment outcomes. Although our results proved that both T-SA1 and T-SA2 could internalize into the cells and enter lysosome degradation pathway, many studies considered that HER2 was resistant in internalization due to several mechanisms such as membrane protrusions and efficient recycle of internalized HER2 to membrane. ${ }^{70,79-81}$ It has been demonstrated that the stability of HER2 is associated with HSP90's function, and HSP90 inhibitors played an important role in rapid downregulation of HER2 from the surface of cells. ${ }^{82-84}$ Meanwhile, studies by us have demonstrated that the internalization efficiency and lysosomal traffic of scFv-HSA fusion antibodies-HER2 complexes in HER2-positive tumor cells could be significantly improved by combining with HSP90 inhibitor 17-AAG (data not shown). This result is consistent with the view of Raja et al. ${ }^{85}$ It turned out that the potential combination of anti-HER2 scFv-HSA fusion antibody-based ADCs with an HSP90 inhibitor may provide a novel strategy to improve the therapeutic efficacy of cancer.

In addition, the valence of an antibody also plays a very important role in its tumor targeting capability and biodistribution. Although we speculated that the T-SA2-DM1 with bivalent antigen-binding sites should exhibit better antitumor activity, the in vivo study proved to be opposite.There are many reasons for this result, such as the molecular weight and size, the affinity, the stability of conformation and pharmacokinetics of antibody in vivo. Compared with an intact antibody, scFv presents a greater extent of aggregation. Moreover, an additional interaction occurring between $\mathrm{V}_{\mathrm{H}}$ and $\mathrm{V}_{\mathrm{L}}$ domains of two scFvs gives rise to form polymer more easily, ${ }^{86,87}$ so that scFv with bivalent antigenbinding sites is less stable. This might be the one reason for the slightly inferior affinity of T-SA2 compared with T-SA1. On the other hand, the arrangement order of $V_{H}$ and $V_{L}$ domains and the type of flexible linker are also important factors affecting the activity and stability of antibody. ${ }^{88-91}$ Therefore, the design of fusion antibodies needs to be further optimized in the future. On the basis of the results of in vivo distribution, the tumor tissue accumulation of T-SA1 was the most obvious. Therefore, the penetrability of antibody in tumor tissue is also the key factor influencing the therapeutic efficacy, and the related mechanism remains elusive and is worth further study. Furthermore, engineered antibodies have a variety of conformations, and our designed scFv-HSA fusion antibodies have only two. In the future, we will construct the preferred engineered antibodies through various screening of targeting ability, affinity, stability, penetrability and pharmacokinetic in vivo.

ADCs comprise three key components: an antibody conjugated to a high cytotoxicity compound via a linker. The antibody allows precise targeting of a drug to tumor cells. Beyond that, linker technology ensures the controllable and effective release of the drug in target cells rather than in plasma or normal tissues. Following the progress in ADCs development, a series of candidates may be screened out from the various combinations of three components to maximize drug delivery and to limit side effects at the same time. In conclusion, our designing strategy of ADCs based on scFv-HSA fusion antibody demonstrated the potential for applications in cancer therapy. Therefore, the structure optimization of antibody and screening of various linkers as well as agents deserve further exploration.

\section{ACKNOWLEDGEMENTS}

This study was financially supported by the National Science Foundation of China (nos 81372822, 81402564 and 81572995), National High Technology Research and Development Program of China (no. 2015AA020904) and Guangdong Innovative Research Team Program (no. 2011Y073).

\section{AUTHOR CONTRIBUTIONS}

$\mathrm{HZ}$ designed and performed the experiments, analyzed the data, and wrote the manuscript; YXW, YPW, YQY and XZC provided technical supports; and XHJ performed the binding affinity experiment. YJP, LY and RXW performed internalization experiments as assistants. YRT and YYF performed in vivo experiments as assistants; $\mathrm{QHL}, \mathrm{WRL}, \mathrm{WTL}, \mathrm{YHK}, \mathrm{SLY}$ and $\mathrm{YL}$ assisted in preparing laboratory appliance and reagents. JLY conceived and directed the project with assistance from LTG and MW.

\section{COMPETING INTERESTS}

The authors declare no conflict of interest.

\section{REFERENCES}

1 Feld J, Barta SK, Schinke C, Braunschweig I, Zhou Y, Verma A. Linked-in: design and efficacy of antibody drug conjugates in oncology. Oncotarget 2013; 4: 397-412.

2 Casi G, Neri D. Antibody-drug conjugates: basic concepts, examples and future perspectives. J Control Release 2012; 161: 422-428.

3 Flemming A. Antibody engineering: fine-tuning antibody-drug conjugates. Nat Rev Drug Discov 2014; 13: 178-178.

4 Sievers EL, Senter PD. Antibody-drug conjugates in cancer therapy. Annu Rev Med 2013; 64: 15-29.

5 Crunkhorn S. Drug design: increasing stability of ADCs. Nat Rev Drug Discov 2014; 13: 812-812.

6 de Claro RA, McGinn K, Kwitkowski V, Bullock J, Khandelwal A, Habtemariam B et al. US Food and Drug Administration approval summary: brentuximab vedotin for the treatment of relapsed Hodgkin lymphoma or relapsed systemic anaplastic large-cell lymphoma. Clin Cancer Res 2012; 18: 5845-5849.

7 Mathew J, Perez EA. Trastuzumab emtansine in human epidermal growth factor receptor 2-positive breast cancer: a review. Curr Opin Oncol 2011; 23: 594-600. 
8 Shih C, Padhy L, Murray M, Weinberg RA. Transforming genes of carcinomas and neuroblastomas introduced into mouse fibroblasts. Nature 1981; 290: 261-264.

9 Rubin I, Yarden Y. The basic biology of HER2. Ann Oncol 2001; 12(suppl 1): S3-S8.

10 Nuti M, Bellati F, Visconti V, Napoletano C, Domenici L, Caccetta J et al. Immune effects of trastuzumab. J Cancer 2011; 2: 317-323.

11 Yarden Y, Sliwkowski MX. Untangling the ErbB signalling network. Nat Rev Mol Cell Biol 2001; 2: 127-137.

12 Jørgensen JT, Hersom M. HER2 as a prognostic marker in gastric cancer-a systematic analysis of data from the literature. J Cancer 2012; 3: 137-144.

13 Verri E, Guglielmini P, Puntoni M, Perdelli L, Papadia A, Lorenzi P et al. HER2/neu oncoprotein overexpression in epithelial ovarian cancer: evaluation of its prevalence and prognostic significance. Oncology 2005; 68: 154-161.

14 Grob TJ, Kannengiesser I, Tsourlakis MC, Atanackovic D, Koenig AM, Vashist YK et al. Heterogeneity of ERBB2 amplification in adenocarcinoma, squamous cell carcinoma and large cell undifferentiated carcinoma of the lung. Mod Pathol 2012; 25: 1566-1573.

15 Iqbal N, Iqbal N. Human epidermal growth factor receptor 2 (HER2) in cancers: overexpression and therapeutic implications. Mol Biol Int 2014; 2014: 852748.

16 Yoon HH, Shi Q, Sukov WR, Wiktor AE, Khan M, Sattler CA et al. Association of HER2/ErbB2 expression and gene amplification with pathologic features and prognosis in esophageal adenocarcinomas. Clin Cancer Res 2012; 18: 546-554.

17 Piccart-Gebhart MJ, Procter M, Leyland-Jones B, Goldhirsch A, Untch M, Smith I et al. Trastuzumab after adjuvant chemotherapy in HER2-positive breast cancer. N Engl J Med 2005; 353: 1659-1672.

18 Tan AR, Swain SM. Ongoing adjuvant trials with trastuzumab in breast cancer. Semin Oncol 2003; 30(5 Suppl 16): 54-64.

19 Bang Y-J, Van Cutsem E, Feyereislova A, Chung HC, Shen L, Sawaki A et al. Trastuzumab in combination with chemotherapy versus chemotherapy alone for treatment of HER2-positive advanced gastric or gastro-oesophageal junction cancer (ToGA): a phase 3, open-label, randomised controlled trial. Lancet 2010; 376: $687-697$

20 Hubalek M, Brantner C, Marth $C$. Role of pertuzumab in the treatment of HER2positive breast cancer. Breast Cancer 2012; 4: 65-73.

21 Moya-Horno I, Cortés J. The expanding role of pertuzumab in the treatment of HER2-positive breast cancer. Breast Cancer 2015; 7: 125.

22 Boyraz B, Sendur MA, Aksoy S, Babacan T, Roach EC, Kizilarslanoglu MC et al. Trastuzumab emtansine (T-DM1) for HER2-positive breast cancer. Curr Med Res Opin 2013; 29: 405-414.

23 Lambert JM, Chari RV. Ado-trastuzumab emtansine (T-DM1): an antibody-drug conjugate (ADC) for HER2-positive breast cancer. J Med Chem 2014; 57: 6949-6964.

24 Geyer CE, Forster J, Lindquist D, Chan S, Romieu CG, Pienkowski T et al. Lapatinib plus capecitabine for HER2-positive advanced breast cancer. N Engl J Med 2006; 355: 2733-2743.

25 Cetin B, Benekli M, Turker I, Koral L, Ulas A, Dane F et al. Lapatinib plus capecitabine for HER2-positive advanced breast cancer: a multicentre study of Anatolian Society of Medical Oncology (ASMO). J Chemother 2014; 26: 300-305.

26 Robidoux A, Tang G, Rastogi P, Geyer CE, Azar CA, Atkins JN et al. Lapatinib as a component of neoadjuvant therapy for HER2-positive operable breast cancer (NSABP protocol B-41): an open-label, randomised phase 3 trial. Lancet Oncol 2013; 14: 1183-1192.

27 Solca F, Dahl G, Zoephel A, Bader G, Sanderson M, Klein C et al. Target binding properties and cellular activity of afatinib (BIBW 2992), an irreversible ErbB family blocker. J Pharmacol Exp Ther 2012; 343: 342-350.

28 Burris HA, Tibbitts J, Holden SN, Sliwkowski MX, Phillips GDL. Trastuzumab emtansine (T-DM1): a novel agent for targeting HER2+ breast cancer. Clin Breast Cancer 2011; 11: 275-282.

29 Burris HA, Rugo HS, Vukelja SJ, Vogel CL, Borson RA, Limentani S et al. Phase II study of the antibody drug conjugate trastuzumab-DM1 for the treatment of human epidermal growth factor receptor 2 (HER2)-positive breast cancer after prior HER2-directed therapy. J Clin Oncol 2011; 29: 398-405.

30 Krop IE, LoRusso P, Miller KD, Modi S, Yardley D, Rodriguez G et al. A phase II study of trastuzumab emtansine in patients with human epidermal growth factor receptor 2-positive metastatic breast cancer who were previously treated with trastuzumab, lapatinib, an anthracycline, a taxane, and capecitabine. J Clin Oncol 2012; 30: 3234-3241.

31 Krop IE, Kim S-B, González-Martín A, LoRusso PM, Ferrero J-M, Smitt M et al. Trastuzumab emtansine versus treatment of physician's choice for pretreated HER2-positive advanced breast cancer (TH3RESA): a randomised, open-label, phase 3 trial. Lancet Oncol 2014; 15: 689-699.

32 Kupchan SM, Komoda Y, Court W, Thomas G, Smith R, Karim A et al. Tumor inhibitors. LXXIII. Maytansine, a novel antileukemic ansa macrolide from Maytenus ovatus. J Am Chem Soc 1972; 94: 1354-1356.
33 Verma S, Miles D, Gianni L, Krop IE, Welslau M, Baselga J et al. Trastuzumab emtansine for HER2-positive advanced breast cancer. N Engl J Med 2012; 367: 1783-1791.

34 Foyil KV, Bartlett NL. Brentuximab vedotin for the treatment of CD30+ lymphomas. Immunotherapy 2011; 3: 475-485.

35 Younes A, Gopal AK, Smith SE, Ansell SM, Rosenblatt JD, Savage KJ et al. Results of a pivotal phase II study of brentuximab vedotin for patients with relapsed or refractory Hodgkin's lymphoma. J Clin Oncol 2012; 30: 2183-2189.

36 Pro B, Advani R, Brice P, Bartlett NL, Rosenblatt JD, Illidge T et al. Brentuximab vedotin (SGN-35) in patients with relapsed or refractory systemic anaplastic largecell lymphoma: results of a phase II study. J Clin Oncol 2012; 30: 2190-2196.

37 Moskowitz CH, Nademanee A, Masszi T, Agura E, Holowiecki J, Abidi MH et al. Brentuximab vedotin as consolidation therapy after autologous stem-cell transplantation in patients with Hodgkin's lymphoma at risk of relapse or progression (AETHERA): a randomised, double-blind, placebo-controlled, phase 3 trial. Lancet 2015; 385: 1853-1862.

38 Azemar M, Schmidt M, Arlt F, Kennel P, Brandt B, Papadimitriou A et al. Recombinant antibody toxins specific for ErbB2 and EGF receptor inhibit the in vitro growth of human head and neck cancer cells and cause rapid tumor regression in vivo. Int J Cancer 2000; 86: 269-275.

39 Cao Y, Marks JD, Huang Q, Rudnick SI, Xiong C, Hittelman WN et al. Single-chain antibody-based immunotoxins targeting Her2/neu: design optimization and impact of affinity on antitumor efficacy and off-target toxicity. Mol Cancer Ther 2012; 11: 143-153.

40 Cao Y, Marks JD, Marks JW, Cheung LH, Kim S, Rosenblum MG. Construction and characterization of novel, recombinant immunotoxins targeting the Her2/neu oncogene product: in vitro and in vivo studies. Cancer Res 2009; 69: 8987-8995.

41 Cao Y, Marks JW, Liu Z, Cheung LH, Hittelman WN, Rosenblum MG. Design optimization and characterization of Her2/neu-targeted immunotoxins: comparative in vitro and in vivo efficacy studies. Oncogene 2014; 33: 429-439.

42 Arbabi-Ghahroudi M, Tanha J, MacKenzie R. Prokaryotic expression of antibodies. Cancer Metastasis Rev 2005; 24: 501-519.

43 Furukawa M, Tanaka R, Chuang VTG, Ishima Y, Taguchi K, Watanabe H et al. Human serum albumin-thioredoxin fusion protein with long blood retention property is effective in suppressing lung injury. J Control Release 2011; 154: 189-195.

44 Hoppmann S, Miao Z, Liu S, Liu H, Ren G, Bao A et al. Radiolabeled affibodyalbumin bioconjugates for HER2-positive cancer targeting. Bioconjug Chem 2011; 22: 413-421.

45 Yao Y, Su X, Xie Y, Wang Y, Kang T, Gou L et al. Synthesis, characterization, and antitumor evaluation of the albumin-SN38 conjugate. Anti-cancer drugs 2013; 24: 270-277.

46 Kratz F, Warnecke A, Scheuermann K, Stockmar C, Schwab J, Lazar P et al. Probing the cysteine-34 position of endogenous serum albumin with thiol-binding doxorubicin derivatives. Improved efficacy of an acid-sensitive doxorubicin derivative with specific albumin-binding properties compared to that of the parent compound. J Med Chem 2002; 45: 5523-5533.

47 Kratz F, Mansour A, Soltau J, Warnecke A, Fichtner I, Unger C et al. Development of albumin-binding doxorubicin prodrugs that are cleaved by prostate-specific antigen. Arch Pharm 2005; 338: 462-472.

48 Kratz F. Albumin as a drug carrier: design of prodrugs, drug conjugates and nanoparticles. J Control Release 2008; 132: 171-183.

49 Cai Z, Fu T, Nagai Y, Lam L, Yee M, Zhu Z et al. scFv-based "grababody" as a general strategy to improve recruitment of immune effector cells to antibodytargeted tumors. Cancer Res 2013; 73: 2619-2627.

50 Longva KE, Pedersen NM, Haslekås C, Stang E, Madshus IH. Herceptin-induced inhibition of ErbB2 signaling involves reduced phosphorylation of Akt but not endocytic down-regulation of ErbB2. Int J Cancer 2005; 116: 359-367.

51 Raja SM, Clubb RJ, Bhattacharyya M, Dimri M, Cheng H, Pan W et al. A combination of Trastuzumab and 17-AAG induces enhanced ubiquitinylation and lysosomal pathway-dependent ErbB2 degradation and cytotoxicity in ErbB2overexpressing breast cancer cells. Cancer Biol Ther 2008; 7: 1630-1640.

52 Hashizume T, Fukuda T, Nagaoka T, Tada H, Yamada H, Watanabe K et al. Cell type dependent endocytic internalization of ErbB2 with an artificial peptide ligand that binds to ErbB2. Cell Biol Int 2008; 32: 814-826.

53 Belimezi MM, Papanastassiou D, Merkouri E, Baxevanis CN, Mamalaki A. Growth inhibition of breast cancer cell lines overexpressing Her2/neu by a novel internalized fully human Fab antibody fragment. Cancer Immunol Immunother 2006; 55: 1091-1099.

54 Zhu X, Bidlingmaier S, Hashizume R, James CD, Berger MS, Liu B. Identification of internalizing human single-chain antibodies targeting brain tumor sphere cells. Mol Cancer Ther 2010; 9: 2131-2141.

55 Sommaruga S, Lombardi A, Salvadè A, Mazzucchelli S, Corsi F, Galeffi P et al. Highly efficient production of anti-HER2 scFv antibody variant for targeting breast cancer cells. Appl Microbiol Biotechnol 2011; 91: 613-621. 
56 Kramer-Marek G, Kiesewetter DO, Capala J. Changes in HER2 expression in breast cancer xenografts after therapy can be quantified using PET and 18 F-labeled affibody molecules. J Nucl Med 2009; 50: 1131-1139.

57 Phillips GDL, Li G, Dugger DL, Crocker LM, Parsons KL, Mai E et al. Targeting HER2-positive breast cancer with trastuzumab-DM1, an antibody-cytotoxic drug conjugate. Cancer Res 2008; 68: 9280-9290.

58 Zhang M, Qiu Z, Li Y, Yang Y, Zhang Q, Xiang Q et al. Construction and characterization of a recombinant human beta defensin 2 fusion protein targeting the epidermal growth factor receptor: in vitro study. Appl Microbiol Biotechnol 2013; 97: 3913-3923.

59 Ducry L, Stump B. Antibody-drug conjugates: linking cytotoxic payloads to monoclonal antibodies. Bioconjug Chem 2009; 21: 5-13.

60 Backliwal G, Hildinger M, Hasija V, Wurm FM. High-density transfection with HEK-293 cells allows doubling of transient titers and removes need for a priori DNA complex formation with PEl. Biotechnol Bioeng 2008; 99: 721-727.

61 Baldi L, Hacker DL, Adam M, Wurm FM. Recombinant protein production by largescale transient gene expression in mammalian cells: state of the art and future perspectives. Biotechnol Lett 2007; 29: 677-684.

62 Cheng L, Sun X, Yi X, Zhang Y. Large-scale plasmid preparation for transient gene expression. Biotechnol Lett 2011; 33: 1559-1564.

63 Fliedl L, Kaisermayer C. Transient gene expression in HEK293 and vero cells immobilised on microcarriers. J Biotechnol 2011; 153: 15-21.

64 Erickson HK, Park PU, Widdison WC, Kovtun YV, Garrett LM, Hoffman K et al. Antibody-maytansinoid conjugates are activated in targeted cancer cells by lysosomal degradation and linker-dependent intracellular processing. Cancer Res 2006; 66: 4426-4433.

65 Xie H, Audette C, Hoffee M, Lambert JM, Blättler WA. Pharmacokinetics and biodistribution of the antitumor immunoconjugate, cantuzumab mertansine (huC242-DM1), and its two components in mice. J Pharmacol Exp Ther 2004; 308: 1073-1082.

66 Hamblett KJ, Senter PD, Chace DF, Sun MM, Lenox J, Cerveny CG et al. Effects of drug loading on the antitumor activity of a monoclonal antibody drug conjugate. Clin Cancer Res 2004; 10: 7063-7070.

67 Stephan J-P, Chan P, Lee C, Nelson C, Elliott JM, Bechtel C et al. Anti-CD22-MCC DM1 and MC-MMAF conjugates: impact of assay format on pharmacokinetic parameters determination. Bioconjug Chem 2008; 19: 1673-1683.

68 Hayes DF, Yamauchi H, Broadwater G, Cirrincione CT, Rodrigue SP, Berry DA et al. Circulating HER-2/erbB-2/c-neu (HER-2) extracellular domain as a prognostic factor in patients with metastatic breast cancer cancer and leukemia group B study 8662. Clin Cancer Res 2001; 7: 2703-2711.

69 Molina MA, Sáez R, Ramsey EE, Garcia-Barchino M-J, Rojo F, Evans AJ et al. $\mathrm{NH}(2)$-terminal truncated HER-2 protein but not full-length receptor is associated with nodal metastasis in human breast cancer. Clin Cancer Res 2002; 8: 347-353.

70 Austin CD, De Mazière AM, Pisacane PI, van Dijk SM, Eigenbrot C, Sliwkowski MX et al. Endocytosis and sorting of ErbB2 and the site of action of cancer therapeutics trastuzumab and geldanamycin. Mol Biol Cell 2004; 15: 5268-5282.

71 Huang C, Liu Y, Rokita SE. Targeting duplex DNA with the reversible reactivity of quinone methides. Signal Transduct Target Ther 2016; 1: 16009.

72 Smaglo BG, Aldeghaither D, Weiner LM. The development of immunoconjugates for targeted cancer therapy. Nat Rev Clin Oncol 2014; 11: 637-648.

73 Yokota T, Milenic DE, Whitlow M, Wood JF, Hubert SL, Schlom J. Microautoradiographic analysis of the normal organ distribution of radioiodinated single-chain Fv and other immunoglobulin forms. Cancer Res 1993; 53: 3776-3783.

74 Pasquetto MV, Vecchia L, Covini D, Digilio R, Scotti C. Targeted drug delivery using immunoconjugates: principles and applications. J Immunother 2011; 34: 611-628.

75 Liu F, Mu J, Xing B. Recent advances on the development of pharmacotherapeutic agents on the basis of human serum albumin. Curr Pharm Des 2015; 21: 1866-1888.
76 Rogers B, Dong D, Li Z, Li Z. Recombinant human serum albumin fusion proteins and novel applications in drug delivery and therapy. Curr Pharm Des 2015; 21: 1899-1907.

77 Qi W-W, Yu H-Y, Guo H, Lou J, Wang Z-M, Liu P et al. Doxorubicin-loaded glycyrrhetinic acid modified recombinant human serum albumin nanoparticles for targeting liver tumor chemotherapy. Mol Pharm 2015; 12: 675-683.

78 Müller D, Karle A, Meißburger B, Höfig I, Stork R, Kontermann RE. Improved pharmacokinetics of recombinant bispecific antibody molecules by fusion to human serum albumin. J Biol Chem 2007; 282: 12650-12660.

79 Hommelgaard AM, Lerdrup $M$, van Deurs B. Association with membrane protrusions makes ErbB2 an internalization-resistant receptor. Mol Biol Cell 2004; 15: 1557-1567.

80 Rudnick SI, Lou J, Shaller CC, Tang Y, Klein-Szanto AJ, Weiner LM et al. Influence of affinity and antigen internalization on the uptake and penetration of anti-HER2 antibodies in solid tumors. Cancer Res 2011; 71: 2250-2259.

81 Bertelsen V, Stang E. The mysterious ways of ErbB2/HER2 trafficking. Membranes 2014; 4: 424-446.

82 Citri A, Kochupurakkal BS, Yarden Y. The achilles heel of ErbB-2/HER2: regulation by the $\mathrm{Hsp} 90$ chaperone machine and potential for pharmacological intervention. Cell Cycle 2004; 3: 50-59.

83 Lerdrup M, Hommelgaard AM, Grandal M, van Deurs B. Geldanamycin stimulates internalization of ErbB2 in a proteasome-dependent way. J Cell Sci 2006; 119 85-95.

84 Pedersen NM, Madshus IH, Haslekås C, Stang E. Geldanamycin-induced down-regulation of ErbB2 from the plasma membrane is clathrin dependent but proteasomal activity independent. Mol Cancer Res 2008; 6: 491-500.

85 Raja SM, Desale SS, Mohapatra B, Luan H, Soni K, Zhang J et al. Marked enhancement of lysosomal targeting and efficacy of ErbB2-targeted drug delivery by HSP90 inhibition. Oncotarget 2016; 7: 10522-10535.

86 Perisic O, Webb PA, Holliger P, Winter G, Williams RL. Crystal structure of a diabody, a bivalent antibody fragment. Structure 1994; 2: 1217-1226.

87 Arndt MA, Krauss J, Rybak SM. Antigen binding and stability properties of non-covalently linked anti-CD22 single-chain Fv dimers. FEBS Lett 2004; 578: 257-261.

88 Huston JS, Mudgett-Hunter M, Tai MS, McCartney J, Warren F, Haber E et al. Protein engineering of single-chain Fv analogs and fusion proteins. Methods Enzymol 1991; 203: 46-88.

89 Whitlow M, Bell BA, Feng SL, Filpula D, Hardman KD, Hubert SL et al. An improved linker for single-chain $\mathrm{Fv}$ with reduced aggregation andenhanced proteolytic stability. Protein Eng 1993; 6: 989-995.

90 Lu D, Jimenez X, Witte L, Zhu Z. The effect of variable domainorientation and arrangement on the antigen-binding activity of arecombinant human bispecific diabody. Biochem Biophys Res Commun 2004; 318: 507-513.

91 Sheikholvaezin A, Sandstrom P, Eriksson D, Norgren N, Riklund K, Stigbrand T. Optimizing the generation of recombinant single-chainantibodies against placental alkaline phosphatase. Hybridoma 2006; 25: 181-192.

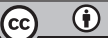

This work is licensed under a Creative Commons Attribution 4.0 International License. The images or other third party material in this article are included in the article's Creative Commons license, unless indicated otherwise in the credit line; if the material is not included under the Creative Commons license, users will need to obtain permission from the license holder to reproduce the material. To view a copy of this license, visit http://creativecommons.org/licenses/ by/4.0/

(c) The Author(s) 2017 